\title{
Functional diversity loss with increasing livestock grazing intensity in drylands: the mechanisms and their consequences depend on the taxa
}

\author{
Verónica Chillo ${ }^{1,2 * \dagger}$, Ricardo A. Ojeda ${ }^{1}$, Virginia Capmourteres ${ }^{2}$ and Madhur Anand ${ }^{2}$ \\ ${ }^{1}$ Biodiversity Research Group, Instituto Argentino de Investigaciones de Zonas Áridas (IADIZA), CONICET CCT- \\ Mendoza, Mendoza CC507, Argentina; and ${ }^{2}$ Global Ecological Change Laboratory, School of Environmental \\ Sciences, University of Guelph, Guelph, ON N1G 2W1, Canada
}

\section{Summary}

1. Overgrazing is one of the main drivers of desertification in drylands, and livestock production is expected to increase in the next decades. The analysis of functional diversity can clarify the effects of increasing livestock grazing on ecosystem functioning.

2. We assess the effect of livestock grazing intensity on the relationship between taxonomic diversity $\left(\mathrm{TD}_{\mathrm{H}}\right)$ and functional diversity $\left(\mathrm{FD}_{\mathrm{Q}}\right)$ of plants, ants and small mammals, as well as on within-trait diversity. We compared results using two indices of taxonomic diversity (Shannon and Simpson indices). We used structural equation modelling (SEM) to assess the causal relationship between grazing intensity, $\mathrm{TD}_{\mathrm{H}}, \mathrm{FD}_{\mathrm{Q}}$ and decomposition rate for each taxa.

3. Correlation between $\mathrm{TD}_{\mathrm{H}} \mathrm{vs}$. $\mathrm{FD}_{\mathrm{Q}}$ varied across assemblages and seasons, but was consistent between different indices of taxonomic diversity. A similar trajectory of $\mathrm{TD}_{\mathrm{H}} \mathrm{vs}$. $\mathrm{FD}_{\mathrm{Q}}$ under landuse intensification was found for all taxa, with a correlated loss of species and functional traits. Also, within-trait diversity was negatively affected by increasing grazing pressure. Vegetation and small mammal SEM models show that increasing grazing intensity had a strong and direct effect on decomposition rate. The ant SEM model was the only one that showed an indirect effect of grazing on decomposition through $\mathrm{FD}_{\mathrm{Q}}$. $\mathrm{TD}_{\mathrm{H}}$ had no effect on decomposition for either taxa.

4. We found higher niche differentiation in animal than in plant assemblages. In vegetation, several species seem to have similar trait diversity (i.e. redundancy), perhaps due to a dominant role of environmental constraints. These results were consistent among diversity indices. But increasing disturbance negatively affected $\mathrm{TD}_{\mathrm{H}} \mathrm{vs}$. $\mathrm{FD}_{\mathrm{Q}}$ in all assemblages in a similar way. Livestock grazing affected decomposition rate directly, and indirectly only through the effect of ant $\mathrm{FD}_{\mathrm{Q}}$.

5. Synthesis and applications. Under increasing grazing intensity, all plant and animal assemblages respond with a mirrored reduction in taxonomic diversity and functional diversity, although vegetation seems to have higher functional redundancy. Our results are robust to diversity indices, and show that several taxa respond similarly to land-use intensification, despite differences in the mechanism behind it. This may facilitate sustainable management. Notably, increasing grazing intensity affects decomposition rate through a stronger direct than indirect effect. The stronger direct effect of livestock on decomposition rate, rather than indirectly through functional diversity, suggests that changes in structure may be more important than changes in community composition.

Key-words: ants, arid rangeland management, decomposition rate, drylands, functional effect traits, functional redundancy, Monte desert, overgrazing, small mammals, vegetation

\footnotetext{
*Correspondence author. E-mail: mchillo@unrn.edu.ar

${ }^{\dagger}$ Present address: Instituto de Investigaciones en Recursos Naturales, Agroecología y Desarrollo Rural (IRNAD), Universidad Nacional de Río Negro Sede Andina, Rio Negro, Argentina
}

\section{Introduction}

Current global increases in agricultural demands are often achieved by expanding agriculture to marginal and previously less managed areas, causing the displacement of 
livestock production to more arid regions (Thornton 2010). Arid, semi-arid and subhumid ecosystems (drylands hereafter) collectively occupy almost $41 \%$ of the world's land surface and are highly vulnerable to desertification (Maestre et al. 2012), an ecological change characterized by the loss of fertile soil that diminishes biodiversity and primary and secondary productivity of the system. Overgrazing is among the main causes of desertification because it diminishes vegetation cover and disrupts important ecological processes such as grass recruitment and nutrient cycling (Reynolds \& Stafford Smith 2001). Livestock grazing is a complex disturbance to investigate. There are several factors involved in biodiversity response, such as vegetation type within the landscape, climatic seasonality, grazer identity and stocking rates, paddock design and grazing management, among many others (Chillo \& Ojeda 2014; Eldridge et al. 2015). In drylands, livestock grazing during dry periods generates a radial gradient of grazing intensity due to the provision of permanent water sources, called a piosphere. Several studies have demonstrated the negative effect of such management, where grazing intensity concentrated close to the watering points diminishes plant and animal species diversity (Landsberg et al. 2003; Hoffman \& James 2011; Chillo \& Ojeda 2014)

In order to understand the effects of livestock grazing on ecological processes, it is necessary to consider aspects of biodiversity besides species richness and abundance. It is, for example, well known that diversity influences ecosystem functioning through the type, range and relative abundance of functional traits, defined as the characteristics of an organism that determine its effect over ecosystem processes (Cadotte, Carscadden \& Mirotchnick 2011). The identification of functional traits allows us to understand the effect of species loss on the ecological processes where they play a role, and thus over the functioning of the ecosystem as a whole (Cardinale et al. 2012). Species diversity has long been used as an indicator of the conservation status of ecosystems, but higher species diversity does not always imply higher diversity of functional traits (Cadotte, Carscadden \& Mirotchnick 2011). Rather, the relationship between species and functional traits is variable along gradients of abiotic and biotic factors because of the occurrence of different mechanisms of community assemblage. For example, it has been found that environmental constraints (i.e. drought) may be more important than grazing disturbance in structuring communities in dry habitats (Carmona et al. 2012). It has also been proposed that in communities with high functional redundancy (several species with similar functional roles), the loss of species richness due to an increase in environmental constrains may not result in a decrease in functional diversity if species loss is randomly distributed across functional groups (Mayfield et al. 2010). Although drylands have been described as systems containing high functional redundancy (Carmona et al. 2012), species loss within functional groups has been found to be associated with the diversity in response traits (Chillo, Anand \& Ojeda 2011), and not in a random way.

Livestock grazing disturbance affects different plant functional traits, with several traits being indicators of this disturbance (i.e. short height and ruderal life forms) (Díaz et al. 2007). Moreover, variations in precipitation and disturbance intensity have been found to be important factors affecting the response of plant functional diversity (Carmona et al. 2012). However, few studies have empirically analysed how these changes in functional diversity affect ecosystem function in natural ecosystems (Valencia et al. 2015), a key link needed to understand the consequences of biodiversity loss. For example, decomposition rates may be a good indicator of ecosystem functioning as they relate to nutrient cycling.

Grazing may affect decomposition rate by changes in microenvironmental conditions (direct effect) and by changes in plant community composition which modifies litter quantity and quality (indirect effect). But the directionality of the effect seems to be highly context dependent (Bardgett \& Wardle 2003). On the one hand, grazing is expected to alter decomposition rate by decreasing plant cover, increasing litter exposure to UV radiation and, thus, photodegradation (Giese et al. 2009). But it also increases soil compaction and reduces infiltration, and together with higher solar exposure, the reduced microsite humidity may decrease microbial activity and reduce decomposition rate (Vaieretti et al. 2010). Also, grazing is expected to increase soil nutrient availability (i.e. dung and urine inputs), thus stimulating decomposition rate (Wardle, Bonner \& Barker 2002). On the other hand, changes in plant functional diversity due to grazing may influence decomposition rate through changes in litter quality (Semmartin et al. 2004). In drylands, grazing had been found to produce lower litter quality (i.e. low $\mathrm{N}$ and high secondary compounds content) and, together with the decrease in litter quantity and soil moisture, negatively affects decomposition rate (Campanella \& Bisigato 2010). Such changes in plant composition may affect animal communities by modifying habitat structure and food availability (Hoffman \& James 2011; Chillo \& Ojeda 2014), which may in turn modify the decomposition rate by altering resource intake and release in space and time (Schmitz et al. 2015).

Although much less is known regarding animal assemblages and human-induced disturbances, a decrease in animal functional diversity with negative effects on ecosystem functioning has been reported (Chillo \& Anand 2012; García \& Martínez 2012). Moreover, it has been found that the effect of land-use changes on the relationship between taxonomic diversity and functional diversity varies between different taxa, being highly complex and context dependent (Anand, Laurence \& Rayfield 2005; Hevia et al. 2015). Thus, the challenge is to consider several trophic levels when analysing the consequences of functional diversity loss, because fauna can also influence key ecosystem processes such as productivity and nutrient 
cycling (Schmitz et al. 2015). Therefore, a key research need is to integrate taxa of different trophic levels in order to examine livestock grazing effects on functional diversity and ecosystem functioning.

The main purpose of this study was to analyse the effect of increasing livestock grazing disturbance on community functional diversity of different taxa (plants, small mammals and ants), and on decomposition rate in the Monte Desert of Argentina. We also analyse the variability of community response given by the marked seasonality that characterizes drylands. Our working hypotheses are as follows: (i) due to the importance of environmental filtering in structuring communities (i.e. drought in drylands) (de Bello et al. 2013), we expect a decoupled relationship between taxonomic diversity and functional diversity (i.e. a decrease in taxonomic diversity will not be mirrored by functional diversity, Carmona et al. 2012), with high redundancy given by stress-tolerant traits; (ii) as traits related to drought tolerance may be similar to those related to grazing tolerance (Quiroga et al. 2010), we hypothesize that increasing grazing intensity will diminish the diversity of trait values at the level of a single trait ('within-trait diversity'), but the diversity of multiple traits at the community level ('across trait diversity') will be diminished in a less significant way; (iii) decomposition rate will be negatively and directly affected by livestock intensity, and indirectly through changes in community functional diversity.

\section{Materials and methods}

\section{STUDY SITE AND SAMPLING DESIGN}

The study was conducted in the Central Monte desert biome of Mendoza province, Argentina $\left(33^{\circ} 46^{\prime} \mathrm{S}, 67^{\circ} 47^{\prime} \mathrm{W}\right)$. The climate is semi-arid and markedly seasonal, with cold dry winters and hot wet summers, with mean annual temperature of $12{ }^{\circ} \mathrm{C}$ and mean annual precipitation of $342.5 \mathrm{~mm}$. Study sites were located within sand dunes, an extensive habitat type of the region. The vegetation is an open xerophytic savanna and shrub land where grasses dominate the herbaceous layer. The dominant management strategy is continuous and extensive cattle grazing around a water source, where main beef production is $3 \mathrm{~kg} \mathrm{ha}^{-1}$ year $^{-1}$ and carrying capacity ranges from 15.3 to $26 \cdot 3$ ha $\mathrm{AU}^{-1}$ (hectares per animal unit) year ${ }^{-1}$ (Guevara et al. 2009). We selected seven different watering points in private rangelands (from 4000 to 8000 ha approx.), each one representing a different grazing gradient $(n=7)$, where stocking rates varied between 18 and 26 ha $\mathrm{AU}^{-1}$. A precise location of each sampling site is available from Chillo et al. (2016).We sampled vegetation, ants and small mammals in each grazing gradient, along a transect originating at the watering point. Ten sampling sites were set up at varying distances $(100,180,290,400,600,850,1200,1800,2400$ and $3200 \mathrm{~m}$ ) from the watering point. These distances were chosen based on previous studies in the area, which reported that utilization during the wet season ranged from $50.4 \%$ at $100 \mathrm{~m}$ from the watering point to $18.6 \%$ at further distances than $3200 \mathrm{~m}$. The relationship fitted a curvilinear function, characterized by a threshold change in cattle usage along the piosphere pattern
(Chillo \& Ojeda 2014). Samples were taken during the dry (MaySeptember) and wet seasons (November-March) over two years (summer 2008 up to winter 2010). Within each sampling site, we visually estimated the percentage of each plant species cover in 10 randomly distributed quadrants of $1 \mathrm{~m}^{2}$. Ants were sampled using four pitfall traps $(9 \mathrm{~cm}$ diameter) placed in a $2 \times 2$ grid, $40 \mathrm{~m}$ apart each and active during three consecutive days. Small mammals were sampled using Sherman live-capture traps and placed in a $4 \times 4$ grid, $10 \mathrm{~m}$ apart each and active during three consecutive nights. Captured individuals were permanently marked in the ear with a small cut and then released. Due to the low abundance of small mammals in the area, we used the total abundance of both consecutive years in our analyses.

The decomposition rate of standard material was calculated as a proxy of the decomposition process by incubating three litterbags (mesh pore diameter of $3 \mathrm{~mm}$ ) containing $1 \mathrm{~g}$ of standard material (cellulose) in the topsoil during 9 weeks (Scherer-Lorenzen 2008). Due to the importance of the microsite effect on decomposition rate (Vaieretti et al. 2010), one litterbag was placed in each of the three main different microsites: under shrub canopy, under grass canopy and in bare soil. We then calculated the mean value of decomposition rate between microsites and obtained one value for each sampling site. After incubation, litterbags were dried at $50{ }^{\circ} \mathrm{C}$ during three days and weighted. Decomposition rate of standard material was calculated as the amount of lost weight per day (Scherer-Lorenzen 2008). This experiment was carried out in three transects (10 sites per transect) during the wet season, where decomposition rates are thought to be higher.

An important methodological aspect of our study was the selection of functional traits related to the ecological processes that were both affected by livestock grazing and related to decomposition rate. The chosen traits (Table 1) are related to microhabitat conditions (humidity, irradiation, etc.), primary and secondary productivity, and nutrient cycling. The selected functional effect traits were those for which information exists in publications or biological collections and that exhibit low or null intraspecific variation, except for body size which was obtained from captured mammals. The trait values/categories used for each species are shown in Table S1, Supporting Information.

\section{DATA ANALYSIS}

\section{Indices of taxonomic diversity and functional diversity}

Taxonomic diversity was analysed via the commonly used Shannon-Weiner index $\left(\mathrm{TD}_{\mathrm{H}}\right)$ (Magurran 2004). Rao's entropy index $\left(\mathrm{FD}_{\mathrm{Q}}\right)$ was chosen to estimate functional diversity, because it allows the use of relative abundances (Botta-Dukát 2005). This was a very important consideration because under low or intermediate levels of grazing disturbance, ants and small mammals may respond only through changes in abundance, but not in species richness (Hoffman \& James 2011; Chillo \& Ojeda 2012). Moreover, since $\mathrm{FD}_{\mathrm{Q}}$ is related to functional richness and functional divergence, it is useful when analysing assemblages with a low number of species (i.e. mammal assemblages) (Mouchet et al. 2010). We used the Gower index to estimate the dissimilarity matrix because it allows for binary, categorical and continuous variables.

Although, as already noticed by de Bello et al. (2016), there is a clear mathematical relationship between Simpson index of diversity 
Table 1. Functional effect traits (and its categories) used to calculate functional diversity of vegetation, ants and small mammals

\begin{tabular}{|c|c|c|}
\hline Taxa & Trait & Category \\
\hline \multirow[t]{22}{*}{ Vegetation } & \multirow[t]{5}{*}{ Growth form } & Grass \\
\hline & & Forb \\
\hline & & Subshrub \\
\hline & & Shrub \\
\hline & & Tree \\
\hline & \multirow[t]{3}{*}{ Life cycle } & Annual \\
\hline & & Deciduous \\
\hline & & Perennial \\
\hline & \multirow[t]{3}{*}{ Leaf size } & Small $(<2 \mathrm{~cm})$ \\
\hline & & Medium $(2-5 \mathrm{~cm})$ \\
\hline & & $\operatorname{Big}(>5 \mathrm{~cm})$ \\
\hline & \multirow[t]{2}{*}{ Main root system } & Taproot \\
\hline & & Lateral \\
\hline & \multirow[t]{4}{*}{ Lateral spread } & Single shoot \\
\hline & & Several stems \\
\hline & & Stolons or rhizomes \\
\hline & & Tussock (caespitose) \\
\hline & \multirow[t]{3}{*}{ Leaf texture } & Tough \\
\hline & & Intermediate \\
\hline & & Membranous \\
\hline & Leguminosae & Legume/non legume \\
\hline & Storage organs & Yes/no \\
\hline \multirow[t]{13}{*}{ Ants } & \multirow[t]{5}{*}{ Foraging strategy } & Opportunistic \\
\hline & & Generalistic \\
\hline & & Granivorous \\
\hline & & Leaf-cutter \\
\hline & & Specialist predator \\
\hline & \multirow[t]{3}{*}{ Habitat type } & Open \\
\hline & & Closed \\
\hline & & Intermediate \\
\hline & \multirow{2}{*}{ Climatic preference } & Warm \\
\hline & & Humid \\
\hline & Body size & Continuous (mm) \\
\hline & Activity & Ground dwelling \\
\hline & & Canopy \\
\hline \multirow{9}{*}{$\begin{array}{l}\text { Small } \\
\text { mammals }\end{array}$} & \multirow[t]{4}{*}{ Main items in the diet $(\%)$} & Insects \\
\hline & & Seeds \\
\hline & & Leaves \\
\hline & & Others \\
\hline & \multirow[t]{3}{*}{ Escape strategy } & Quadrupedal gait \\
\hline & & Quadrupedal saltation \\
\hline & & Scansorial \\
\hline & Body size & Continuous (gr) \\
\hline & Semifossorial & Yes/no \\
\hline
\end{tabular}

and Rao's entropy index, we have used Shannon-Weiner index because the Simpson index has its own drawbacks in that it is more of a dominance index, giving more weight to common or dominant species and the effects of rare species may not be taking into account. In the study region, there are many species with very low abundances, especially during wet season where annual ephemeral species bloom. Shannon index is sensitive to the occurrence of these species better than Simpson index. Still, to prevent misinterpretations given a potential nonlinear relationship between Shannon index and Rao, we decided to compute parallel analyses using Simpson $\left(\mathrm{TD}_{\mathrm{S}}\right)$ index and compare the results.

We calculated $\mathrm{TD}_{\mathrm{H}}$ and $\mathrm{FD}_{\mathrm{Q}}$ for each assemblage at each distance from the watering point. However, different considerations were taken into account for each assemblage. Plant diversity at each site was computed using the mean value of the 10 samples.
Ant captures of the four pitfall traps were pooled to compute one value per site at each grazing gradient. Since ants often present a problem for quantification due to a clumping of individuals within samples, we transformed abundance to an ordinal scale: $1=1$ ant; $2=2-5$ ants; $3=6-20$ ants; $4=21-50$ ants; $5=51-100$ ants; $6=101-1000$ ants; $7=>1000$ ants. Small mammal abundance for each species was determined by the minimum number alive for the $4 \times 4$ trap grid of each site. All statistical analyses were performed using $\mathrm{R}$ software and FD package.

\section{Relationship between taxonomic diversity and functional diversity}

Our goal was to assess whether taxonomic diversity is a good indicator of functional diversity in these rangelands. Therefore, we performed Pearson correlations between $\mathrm{TD}_{\mathrm{H}}$ and $\mathrm{FD}_{\mathrm{Q}}$ for each assemblage. We consider a correlation coefficient of 0.6 as a threshold to indicate a certain level of congruence between indices (Lovell et al. 2007). We do not consider that a significant correlation is enough because we are comparing different indices for the same field data (i.e. species abundance of the same taxa) and it is highly probable that the correlation would be statistically significant as the trend in the response to increases in grazing pressure should be similar. Moreover, we wanted to assess whether changes in taxonomic diversity due to increased livestock grazing pressure result in similar changes in functional diversity. To do so, we evaluated the trajectory of change in $\mathrm{TD}_{\mathrm{H}}$ vs. $\mathrm{FD}_{\mathrm{Q}}$ between the less modified sites (far from the watering point) and the most disturbed by livestock sites (closer to the watering point), as done by Mayfield et al. (2010). For comparison purpose, we chose to analyse the distances of $3200 \mathrm{~m}$ and $2400 \mathrm{~m}$ as less modified sites. Only the distances of $100 \mathrm{~m}$ and $180 \mathrm{~m}$ were considered as severely disturbed sites, as in previous studies we identified a clear distinction of these distances from the rest of the gradient for the analysed variables. $\mathrm{R}$ scripts are available from Chillo et al. (2016).

\section{Within-trait diversity along grazing gradients}

In order to assess the effect of grazing intensity on each trait, we performed correlations between the diversity of trait values at the level of a single trait ('within-trait' diversity hereafter) and the distance to the watering point (Table 1). At the fine (local) scale, environmental factors were found to mostly influence functional diversity and the dispersion of trait values, rather than the community mean values of a trait (de Bello et al. 2013). Thus, we decided to use the same $\mathrm{FD}_{\mathrm{Q}}$ index, but calculated it over the value of each trait instead of over the value of all of the traits. This index shows the diversity of categories of a trait in each site, and by assessing its correlation with the distance to watering points, we were able to evaluate whether increasing livestock grazing disturbance diminishes the diversity of the categories of each trait.

\section{Grazing intensity effect on biodiversity and decomposition rate}

First, we searched for a function to characterize the effect of grazing intensity on decomposition rate. Following a thorough exploration of the data, we fitted a simple rectangular hyperbola 
function trough maximum likelihood analysis (Bolker 2008). Secondly, in order to evaluate the effect of increasing livestock grazing disturbance on $\mathrm{TD}_{\mathrm{H}}, \mathrm{FD}_{\mathrm{Q}}$ and decomposition rate, we performed Structural equation modelling (SEM). SEM is a modelling technique that allows for exploratory and confirmatory analysis, where an a priori model is contrasted against data and used to infer causation (Grace 2006). We developed and tested a conceptual model (Fig. 3a) for each assemblage. For parameter estimation, we used the maximum likelihood. Three variancecovariance matrices are used in maximum likelihood: the unknown population covariance matrix $(\Sigma)$, the real observed covariance matrix (S) (an estimate of $\Sigma$ ) and the covariance matrix implied by the model $\left(\Sigma^{\prime}\right)$. The iteration process compares $S$ with $\Sigma$ ' and suggests values for structural coefficients such that S is as close to $\Sigma^{\prime}$ as possible (Grace 2006).

We tested for general model fit with a chi-square test (where a non-significant model $P$-value means a good model fit), the comparative fix index (CFI), the standardized root mean residuals (SRMR), and the Tucker-Lewis index (TLI) (Grace 2006). Individual paths between variables were tested with linear regressions, and were significant if $P$-value $<$ level of significance (Grace 2006). We compared models using the Akaike's Information Criterion (AIC), giving priority to those with smaller AIC values. For all models, modification indices were examined to detect notorious discrepancies between a model and data. Analyses were performed using the LAVAAN and SEMPLOT packages in R. R scripts are available from Chillo et al. (2016).

\section{Results}

The relationship $\mathrm{TD}_{\mathrm{H}}$ vs. $\mathrm{FD}_{\mathrm{Q}}$ varied across assemblages and seasons, as there was a higher correlation between indices when considering animal assemblages, especially during wet season and and lower correlation values when plant or ant assemblages during dry season were analysed (Table 2). Similar trends were obtained in the correlation between Simpson $\left(\mathrm{TD}_{\mathrm{S}}\right)$ index with Rao $\mathrm{FD}_{\mathrm{Q}}$, although correlation values were higher for vegetation and lower under dry season (Table S2), compared with $\mathrm{TD}_{\mathrm{H}}$ vs. $\mathrm{FD}_{\mathrm{Q}}$ values. Nevertheless, all assemblages during both seasons showed a similar trajectory of $\mathrm{TD}_{\mathrm{H}}$ vs. $\mathrm{FD}_{\mathrm{Q}}$ during land-use intensification, with a correlated loss of species and functional traits (Fig. 1). Trajectories were the same when $\mathrm{TD}_{\mathrm{S}}$ was considered (Fig. S1). In regard to the response of within-trait diversity to the grazing gradient, most of the traits showed a significant and positive correlation with distance to watering points, with high correlation values (Fig. 2). There were only four traits whose diversity did not vary along the grazing gradient, and notably, the diversity of life cycles and body sizes were among them (Fig. 2).

Increasing grazing intensity had a negative effect on decomposition rate, with a threshold response in distances near the watering point (Fig. 3, stand. coeff.: 0.53). Also, a significant effect of grazing disturbance intensity on $\mathrm{TD}_{\mathrm{H}}, \mathrm{FD}_{\mathrm{Q}}$ and decomposition rate was supported by our models, but varied according to the analysed taxa (Fig. 4, Table 3). In general, increasing grazing intensity (measured as distance to the watering point) had a strong and direct effect on decomposition when considering vegetation (Fig. 4b, Table S3) and small mammals (Fig. 4d, Table S4), but the link was not significant when considering ants (Fig. 4c, Table S5). However, distance did affect the $\mathrm{TD}_{\mathrm{H}}$ of all assemblages and the $\mathrm{FD}_{\mathrm{Q}}$ of vegetation and ants. Despite this, standardized coefficients (used to compare magnitude of effect of different relationships) indicated that the effect of grazing on decomposition, $\mathrm{TD}_{\mathrm{H}}$ or $\mathrm{FD}_{\mathrm{Q}}$ can be different in magnitude for each assemblage. For vegetation, for example, grazing had a stronger effect on $\mathrm{FD}_{\mathrm{Q}}$ that on other variables (stand. coeff.: 0.68). This was different from the ant SEM model, where grazing had a stronger effect on $\mathrm{TD}_{\mathrm{H}}$ (stand. coeff.: 0.67). Also differing, the effect of grazing in the small mammal SEM model mainly affected decomposition (stand. coeff.: 0.52 ) rather than the diversity of small mammals. $\mathrm{TD}_{\mathrm{H}}$ had no effect on decomposition for either taxa, and the effect of $\mathrm{FD}_{\mathrm{Q}}$ on decomposition was significant only for the ant assemblages (Fig. 4). The use of modification indices revealed that the effect of $\mathrm{TD}_{\mathrm{H}}$ on $\mathrm{FD}_{\mathrm{Q}}$ was significant for all assemblages, despite not being considered in our hypothesized SEM model (Fig. 4, Tables S3-S5).

\section{Discussion}

Our main objective was to characterize the relationship between taxonomic diversity and functional diversity for several assemblages of different trophic levels and to analyse the effect of increasing livestock grazing disturbance on community functional diversity and on decomposition rate in the Central Monte desert biome of Argentina. We found that species diversity of animal assemblages was correlated with functional diversity, but the relationship was weaker for plant assemblages. This may be showing higher niche differentiation by animal assemblages than by vegetation, a relationship also found in other ecosystems (Cardinale 2011). Alternatively, our plant community seemed to be characterized by functional redundancy in the analysed traits, perhaps due to the dominant structuring role of environmental constraints (i.e. water limitation), as found for other drylands world-wide (Carmona et al. 2012). Moreover, these results were robust to diversity indices. Although the relationship between taxonomic diversity and functional diversity of different taxa may be characterized by different mechanisms, we found that increasing livestock grazing disturbance negatively

Table 2. Pearson $r$ correlation coefficient and significance $P$ value for the analysed relationships between taxonomic diversity $\left(\mathrm{TD}_{\mathrm{H}}\right)$ and functional diversity $\left(\mathrm{FD}_{\mathrm{Q}}\right)$

\begin{tabular}{lrr}
\hline & Dry season & Wet season \\
\hline Vegetation & $0.33(0.006)$ & $0.4(0.004)$ \\
Ants & $0.48(0.002)$ & $0.66(0.001)$ \\
Small mammals & $0.57(0.001)$ & $0.6(0.003)$ \\
\hline
\end{tabular}



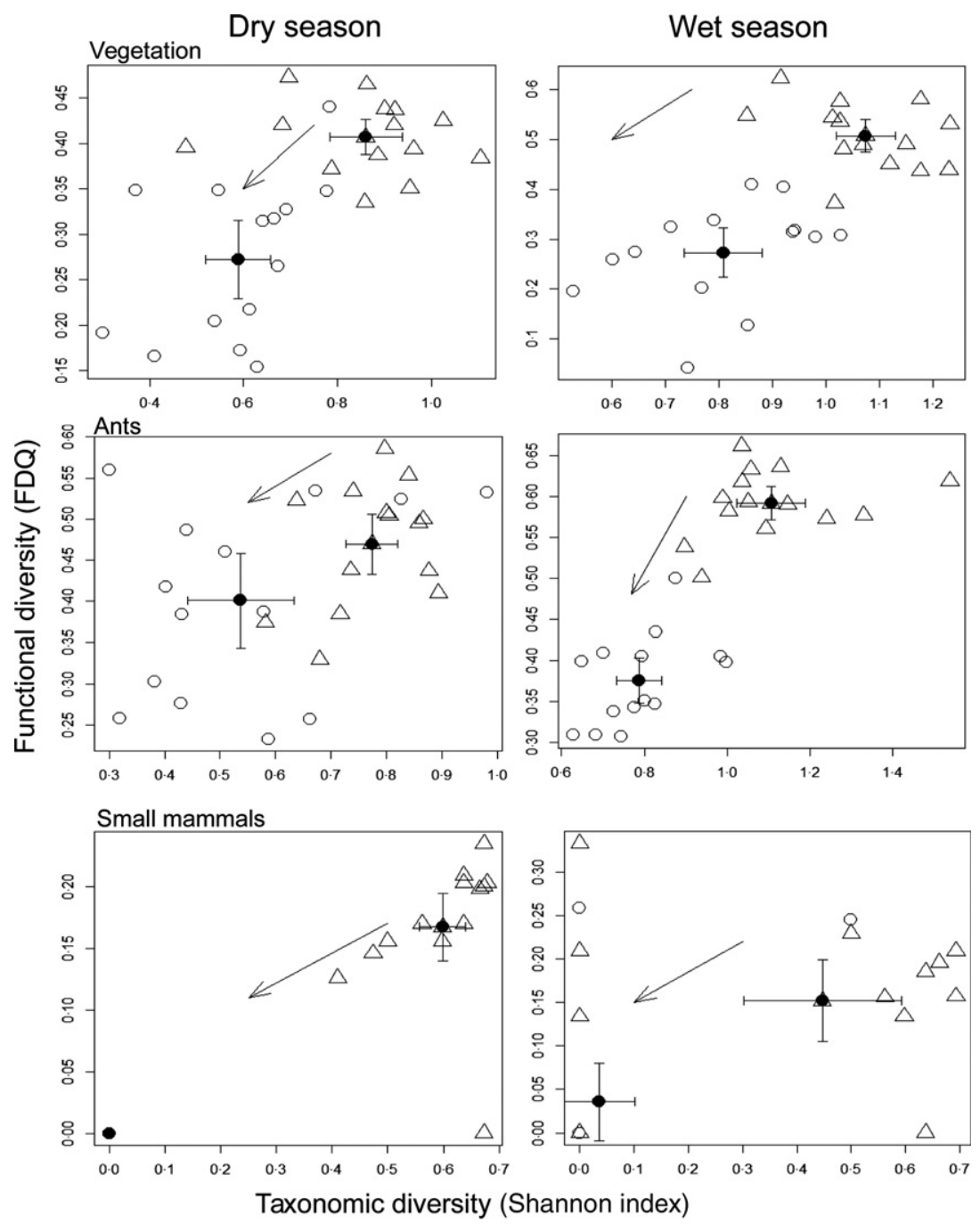

Fig. 1. Changes in taxonomic diversity $\left(\mathrm{TD}_{\mathrm{H}}\right)$ and functional diversity $\left(\mathrm{FD}_{\mathrm{Q}}\right)$ relationship after increasing livestock grazing pressure. Open symbols are individual sampling sites, and closed symbols are the mean of taxonomic diversity and functional diversity relationship for the less and higly disturbed sites. Triangles indicate less disturbed sites (2800 and $3200 \mathrm{~m}$ from the watering point), and circles indicate highly disturbed sites (100 and $180 \mathrm{~m}$ from the watering point). Error bars are $95 \%$ confidence intervals. Arrows illustrate the vector of the trajectory between less disturbed and highly disturbed sites. affected taxonomic diversity and functional diversity in all taxa in the same way. This type of response is expected for communities characterized by a non-random loss of species within particular functional groups, when environmental filters get stronger (Mayfield et al. 2010). Withintrait diversity was strongly affected by livestock grazing, as most traits showed lower diversity of categories at higher grazing pressure. Increasing grazing intensity effect on decomposition rate was negative. Moreover, we found that increasing disturbance may affect decomposition rate mainly through a direct effect of livestock grazing intensity, with notably small effect of functional diversity.

\section{RELATIONSHIP BETWEEN TAXONOMIC DIVERSITY AND FUNCTIONAL DIVERSITY UNDER LAND-USE CHANGE}

Our study shows that the relationship between taxonomic diversity and functional diversity in the Central Monte desert varies across trophic levels and between seasons. Taxonomic diversity may be an appropriate indicator of functional diversity for animal assemblages more than for plant assemblages, as correlations were higher and explained more than $50 \%$ of the variance. This may be showing that animal assemblages present higher functional trait dissimilarities (lower functional redundancy) than vegetation. Some studies have found high functional trait dissimilarity as a common coexistence strategy in drylands mainly due to spatial heterogeneity and temporal variability in resource availability (Chesson et al. 2004). For vegetation, the lower correlation between $\mathrm{TD}_{\mathrm{H}}$ and $\mathrm{FD}_{\mathrm{Q}}$ may show higher functional redundancy than in animal assemblages. Other studies have found higher functional similarity in dry than humid ecosystems due to trait convergence under the combined effect of grazing and drought (Carmona et al. 2012). Our results support these findings only for plant communities, where taxonomically different species may present similar physiological adaptations to cope with stress due to the strong environmental constraints imposed by water deficit (Quiroga et al. 2010).

In the same way, the occurrence of functional similarities is expected for animal assemblages living in stressful environments, which may represent a small functional space (Mouchet et al. 2010) where niche overlap and functional redundancy increases with increasing species 

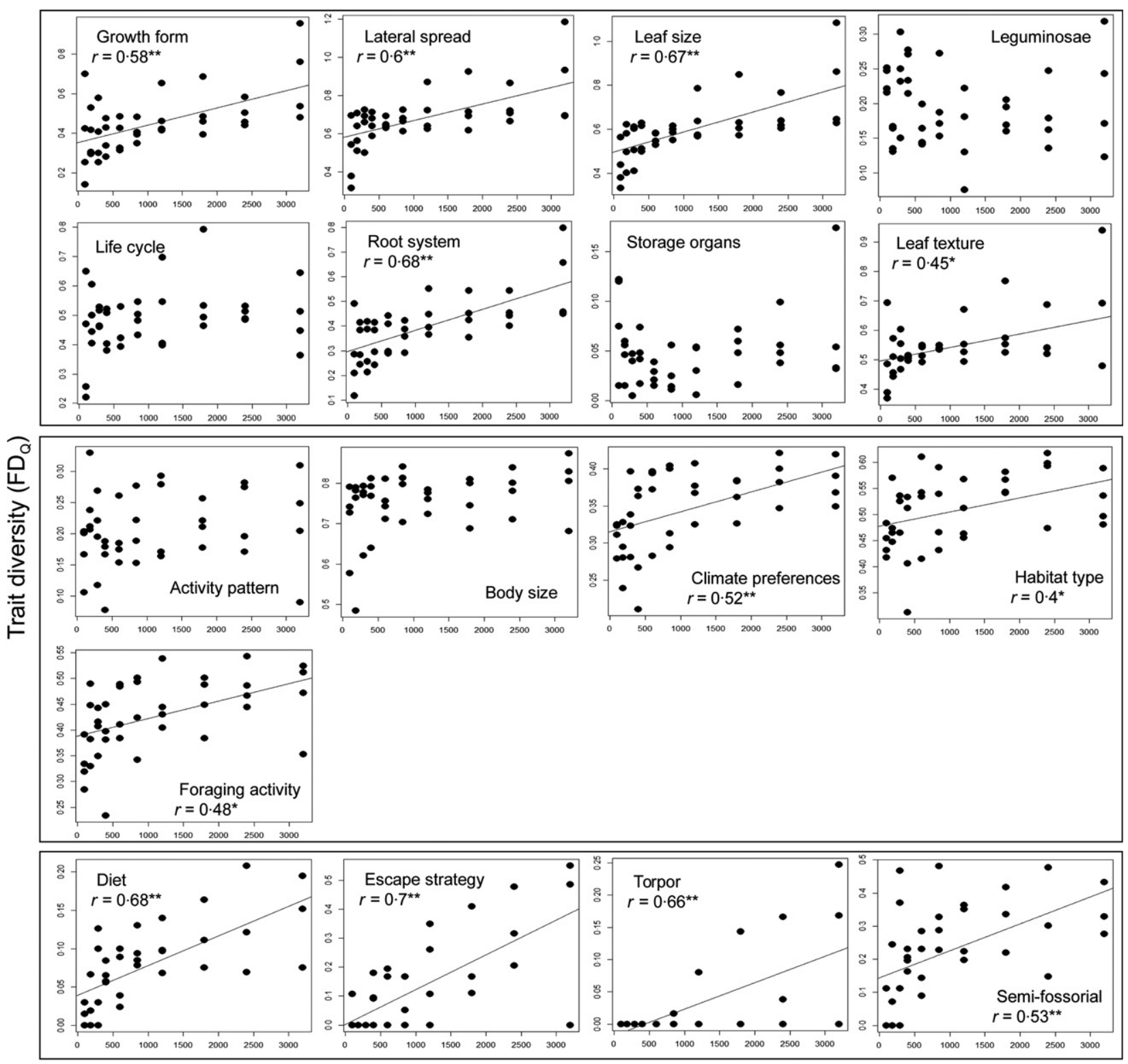

\section{Distance to watering point $(\mathrm{m})$}

Fig. 2. Relationship between the diversity of categories/values of each trait (within-trait $\mathrm{FD}_{\mathrm{Q}}$ ) and distance from a watering point (grazing intensity gradient). Solid lines represent the correlation function. Correlation coefficient (Pearson $r)$ and significance $(* P<0 \cdot 05$, $* * P<0 \cdot 01)$ are also shown.

richness (Cardinale 2011). But contrary to this prediction and to our hypothesis, results show lower functional redundancy than in plant assemblages, as increases in species diversity are mirrored by an increase in functional diversity. Only ant assemblage during dry season may show redundancy, as the correlation between $\mathrm{TD}_{\mathrm{H}}$ and $\mathrm{FD}_{\mathrm{Q}}$ was low, a result also found in other arthropods communities (Moretti, Duelli \& Obrist 2006). In drylands, ant assemblages during dry season are represented by several species adapted to stressful conditions of low resource availability (i.e. several Dorymyrmex spp.). During wet seasons, higher resource availability may allow the occurrence of species with different resource use strategies (niche complementarity) (Table S1). In the case of small mammals, niche complementarity may be a strategy to avoid niche overlap in stressful environments (Rodríguez \& Ojeda 2014). Even during dry season, where only few species persist active, a clear niche segregation can be found (i.e. E. typus and E. moreni differentiate in the main food items) (Table S1). Evidently, increasing resource availability (wet season) results in increases in niche occupancy by new species in all taxa analysed.

Interestingly, the comparison of taxonomical diversity and $\mathrm{FD}_{\mathrm{Q}}$ relationship showed a similar pattern between taxonomic indices, despite the direct relationship found for Simpson index and not for Shannon index (de Bello et al. 2016). For example, plant assemblage showed lower correlation coefficients than animal assemblages using 
either Simpson index or Shannon index. Also, correlation coefficients were lower during dry than wet season for all taxa using either indices (Table S2). Moreover, we found

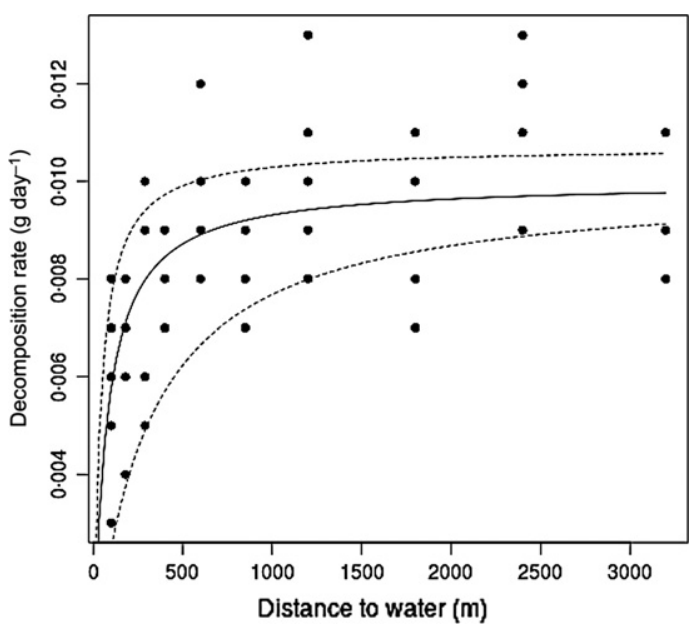

Fig. 3. Relationship between decomposition rate $\left(\mathrm{g} \times\right.$ day $\left.^{-1}\right)$ and distance from the watering point $(\mathrm{m})$ (grazing intensity gradient). Circles represent the mean value of decomposition rate of the three microsites at each sampling site. A hyperbola (solid line) fitted with maximum likelihood (stand. coef.: 0.53 ) and $95 \%$ confident intervals (dotted lines) are shown.

(a)

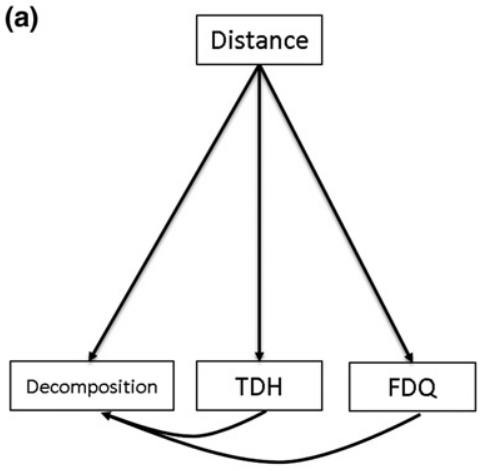

(c)

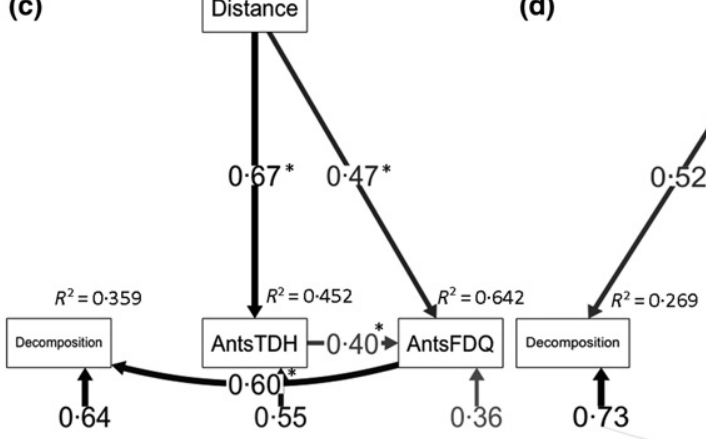

Table 3. Results of model fit tests for structural equation models of vegetation, ants and small mammal assemblages

\begin{tabular}{lcccl}
\hline & \multicolumn{2}{c}{ Obtained values } & \\
\cline { 2 - 3 } $\begin{array}{l}\text { Measure of } \\
\text { model fit }\end{array}$ & Vegetation & $\begin{array}{l}\text { Small } \\
\text { mammals }\end{array}$ & $\begin{array}{l}\text { Ants } \\
\text { values for } \\
\text { good fit }\end{array}$ \\
\hline Chi-square & 0.25 & 0.26 & 0.27 & $>0.05$ \\
CFI & 0.99 & 0.99 & 0.99 & $\begin{array}{l}\text { Near 1 } \\
<0.05\end{array}$ \\
SRMR & 0.04 & 0.03 & 0.04 & $\begin{array}{l}<0.05 \\
\text { Near 1 } \\
\text { TLI }\end{array}$ \\
AIC & 0.98 & 0.97 & 0.98 & Relative \\
\hline
\end{tabular}

that regardless of the taxonomic diversity index used, the relationship between taxonomic diversity and functional diversity - for all taxa in both seasons - showed the same trajectory to increasing grazing disturbance (Figs 1 and S1).

As environmental filtering (aridity) and disturbance (livestock grazing) may constrain biodiversity in similar ways (de Bello et al. 2013), we expected that the loss of taxonomic diversity due to increasing grazing disturbance would not be accompanied by a loss in functional diversity. But our hypothesis was rejected as we found that
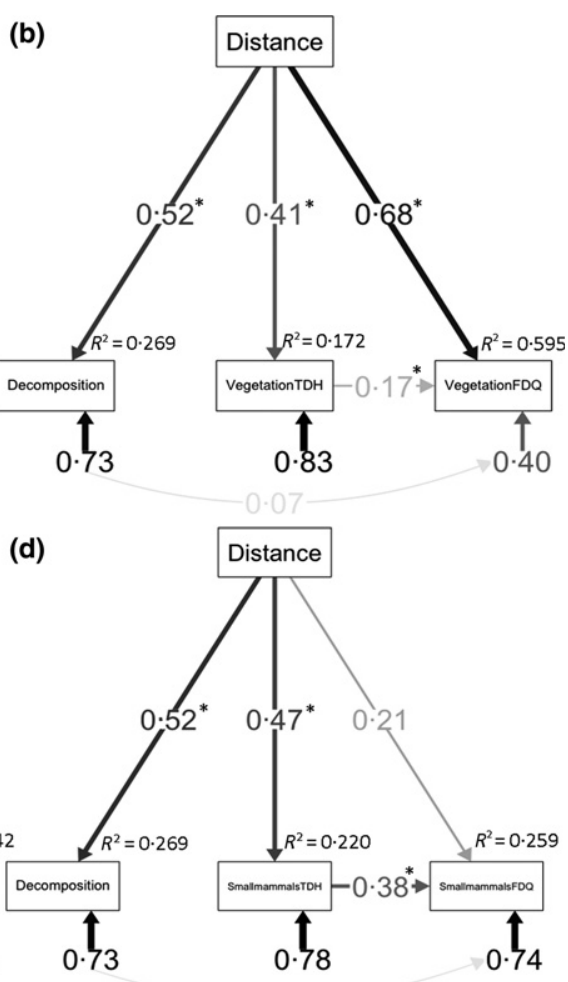

Fig. 4. (a) General hypothesized structural equation model describing the causal relationships that link grazing intensity (distance), taxonomic diversity $\left(\mathrm{TD}_{\mathrm{H}}\right)$ and functional $\left(\mathrm{FD}_{\mathrm{Q}}\right)$ diversity, and decomposition rate (decomposition). (b-d) Best-fitting structural equation models examining direct and indirect relationships for vegetation ( $\mathrm{b} ; P=0 \cdot 250)$, ants $(\mathrm{c} ; P=0 \cdot 266)$ and small mammals $(\mathrm{d}$; $P=0 \cdot 265)$. Variables are shown in boxes; single-headed arrows between variables represent linear regressions; short, single-headed arrows towards variables represent the variance of such variables; long, single-headed arrows between variances of variables depict covariances. The widths of the arrows reflect the strength of dependency between two variables, and standardized path coefficients are shown on the path. Significant paths $(P<0.05)$ are identified with an asterisk. Variance explained by the model $\left(R^{2}\right)$ is shown next to each response variable. 
under increasing grazing intensity all assemblages respond in a similar way, with a reduction in both $\mathrm{TD}_{\mathrm{H}}$ and $\mathrm{FD}_{\mathrm{Q}}$. These results are contrary to those of Hevia et al. (2015), as they found that the relationship was highly variable across taxa and land-use changes. The differences may be due to different scales of analysis, as we analysed sites within the same habitat type (sand dunes in the Central Monte desert) and under the same disturbance (increasing grazing intensity). Our results may show that, although the mechanism that explains the relationship between taxonomic diversity and functional diversity may change between taxa and seasons, land-use affects community assembly processes in the same way (Mayfield et al. 2010). That is, environmental filtering becomes more restrictive due to grazing disturbance, becoming the dominant process regardless of functional redundancy (Chillo, Anand \& Ojeda 2011).

\section{EFFECTS OF GRAZING INTENSITY ON FUNCTIONAL DIVERSITY AND ECOSYSTEM FUNCTIONING}

Confirming our second hypothesis, within-trait diversity of most of the analysed traits was negatively affected by livestock disturbance. The decrease in the diversity of the categories of traits such as growth form, lateral spread, leaf size and root system is of particular concern because of the importance of these plant traits on determining microhabitat condition and litter formation and retention (de Bello, Lepš \& Sebastià 2006; Cornwell et al. 2008). In the same way, in both animal assemblages, increased grazing intensity diminished the diversity of resource capture strategies (i.e. diet, foraging strategy). Moreover, our results show that across trait diversity (the diversity of functional traits) was negatively affected by increasing grazing pressure in sand dunes of the Central Monte desert; but, as we hypothesized, the relationship was weaker than for within-trait diversity (the diversity of categories within individual traits) and highly variable based on biotic and abiotic factors.

When considering the diversity of functional groups, several early warning indicators of desertification have been found such as a decrease in grass cover, or changes in the type of vegetation cover based on the response to the disturbance (Landsberg et al. 2003; Díaz et al. 2007). Few studies, however, have evaluated the effect of increasing livestock grazing on functional diversity beyond the limiting categorical analysis (de Bello, Lepš \& Sebastià 2006; Sasaki et al. 2011; Carmona et al. 2012), and fewer yet have performed integrated studies considering other components of the ecosystem besides just vegetation (Chillo \& Ojeda 2014). To the best of our knowledge, this is the first study that reports a holistic analysis of the effect of increasing livestock grazing on functional diversity of several taxa and on decomposition rate in drylands.

We found a direct effect of livestock disturbance on community taxonomic diversity and functional diversity, as well as on decomposition rate. Livestock grazing in drylands is known to alter community composition towards a community dominated by species with stresstolerant or stress-avoidance strategy (Landsberg et al. 2003; Sasaki et al. 2011; Chillo \& Ojeda 2014). Decomposition rate was predicted to be directly affected as increasing grazing intensity may increase the occurrence and size of bare ground patches and solar exposure, decrease soil moisture and water infiltration (Vaieretti et al. 2010; Cingolani et al. 2013) and reduce leaf litter fall quantity and quality (Campanella \& Bisigato 2010). The net balance of these microenvironmental changes may diminish microbial activity and negatively affect decomposition rate (Vaieretti et al. 2010) despite the potential positive effect that increasing UV exposure (photodegradation) may have had on decomposition rates.

Notably, we found that the main effect of grazing on decomposition is through a direct effect. What we call direct effect may be caused by a negative effect of grazing intensity on plant structure and biomass (Eldridge et al. 2015), which may modify microenvironmental conditions by increasing soil moisture and microbial activity (Giese et al. 2009; Vaieretti et al. 2010); but it can also be other effects not considered in this study like trait main value instead of diversity (Valencia et al. 2015). An indirect effect of grazing on decomposition, through changes in functional diversity, was only found for the ants' model, where the strength of the indirect effect is high enough to make the direct effect insignificant. But we did not find an effect of functional diversity on decomposition when considering vegetation or small mammals, despite several studies reporting this strong indirect effect. In this study, we measured decomposition rate of standard material as a proxy of ecosystem functions related to nutrient cycling and ecosystem productivity (Scherer-Lorenzen 2008). In particular, vegetation is the most important component of biodiversity directly influencing nutrient cycling and other key ecosystem functions in drylands (Maestre et al. 2012). Indirect effects of livestock grazing on decomposition process may occur through changes in litter quality, in microhabitat characteristics and in soil microbial biomass or diversity, given by changes in plant functional trait composition (Bardgett \& Wardle 2003). Our data do not support these hypothesized links, a result found in other drylands (Eldridge et al. 2015), showing that biodiversity relates in complex and nonlinear ways with ecosystem functioning.

\section{IMPLICATIONS FOR RANGELAND MANAGEMENT IN DRYLANDS}

Sustainable management should aim at maintaining species diversity as well as ecosystem functions, and the consideration of functional diversity helps in that way. The occurrence of higher niche differentiation in animal assemblages may facilitate the use of taxonomic diversity as a surrogate of functional diversity. But for vegetation, 
higher functional redundancy may imply that species loss will not reflect the consequences of livestock grazing on ecosystem functioning. Interestingly, under increasing grazing intensity, all assemblages showed a reduction in both taxonomic diversity and functional diversity. This may imply that, when managing small landscape units with similar ecological characteristics and disturbance types, predictions can be made in regard to the consequences of land-use change on community composition. We also found that the relationship between taxonomic diversity and functional diversity is robust to the diversity index used, and may allow managers to use either Shannon index or Simpson index based on their familiarity to one or another. Finally, when considering vegetation we found that the main effect of grazing on decomposition is through a direct effect (i.e. changes in structure and biomass, which may modify microenvironmental conditions) rather than an indirect effects (i.e. changes in litter quality and microhabitat characteristics given by changes functional trait composition). As the effect of grazing disturbance on ecosystem structure may dominate degradation pathways, monitoring structural changes may be a useful tool to design management strategies.

\section{Acknowledgements}

We thank A.M. Cingolani, A. Bisigato, S.M. Giannoni, J.F. Reynolds, M.E. Periago, M.D. Rodríguez, M.S. Albanese, Associate Editor and two anonymous reviewers for helpful comments on early drafts; all field assistants, C. Stasi, J. Antúnez and J.C. Guevara for logistic assistance; and T. Staples for assistant on data analysis. All fauna protocols were approved by Mendoza Province Natural Resources Agency. We acknowledge funding from the Emerging Leaders in the Americas Program (Canada), CONICET and AGENCIA (Argentina).

\section{Data accessibility}

Sampling sites locations, values of all analysed indices for each sampling site and $\mathrm{R}$ scripts for SEM analyses and TD vs. FD trajectory analysis are available from Dryad Digital Repository http://dx.doi.org/10.5061/ dryad.nq2j7 (Chillo et al. 2016). Functional effect trait values/categories for vegetation, ants and small mammals; Pearson $r$ correlation coefficients for TD vs. FD relationship and TD vs. FD trajectory analysis calculated using Simpson index; structural equation models results: uploaded as online supporting information.

\section{References}

Anand, M., Laurence, S. \& Rayfield, B. (2005) Diversity relationships among taxonomic groups in recovering and restored forests. Conservation Biology, 19, 955-962.

Bardgett, R. \& Wardle, D. (2003) Herbivore mediated linkage between aboveground and belowground communities. Ecology, 84, 2258-2268.

de Bello, F., Lepš, J. \& Sebastià, M.T. (2006) Variations in species and functional plant diversity along climatic and grazing gradients. Ecography, 29, 801-810.

de Bello, F., Lavorel, S., Lavergne, S., Albert, C.H., Boulangeat, I., Mazel, F. \& Thuiller, W. (2013) Hierarchical effects of environmental filters on the functional structure of plant communities: a case study in the French Alps. Ecography, 36, 393-402.

de Bello, F., Carmona, C., Leps, J., Szava-Kovats, R. \& Pärtel, M. (2016) Functional diversity through the mean trait dissimilarity: resolving shortcomings with existing paradigms and algorithms. Oecologia, 180, 933-940.
Bolker, B. (2008) Ecological Models and Data in R. Princeton University Press, Princeton, NJ, USA.

Botta-Dukát, Z. (2005) Rao's quadratic entropy as a measure of functional diversity based on multiple traits. Journal of Vegetation Science, 16, 533-540.

Cadotte, M.W., Carscadden, K. \& Mirotchnick, N. (2011) Beyond species: functional diversity and the maintenance of ecological processes and services. Journal of Applied Ecology, 48, 1079-1087.

Campanella, M.A. \& Bisigato, A.J. (2010) What causes changes in plant litter quality and quantity as consequence of grazing in the Patagonian Monte: plant cover reduction or changes in species composition? Austral Ecology, 35, 787-793.

Cardinale, B.J. (2011) Biodiversity improves water quality through niche partitioning. Nature, 472, 86-89.

Cardinale, B.J., Duffy, J.E., Gonzalez, A., Hooper, D.U., Perrings, C., Venail, P. et al. (2012) Biodiversity loss and its impacts on humanity. Nature, 486, 59-67.

Carmona, C.P., Azcárate, F.M., de Bello, F., Ollero, H.S., Lepš, J. \& Peco, B. (2012) Taxonomical and functional diversity turnover in Mediterranean grasslands: interactions between grazing, habitat type and rainfall. Journal of Applied Ecology, 49, 1084-1093.

Chesson, P., Gebauer, R.L.E., Schwinning, S., Huntly, N., Wiegand, K., Ernest, M.S.K., Sher, A., Novoplansky, A. \& Weltzin, J.F. (2004) Resource pulses, species interactions, and diversity maintenance in arid and semi-arid environments. Oecologia, 141, 236-253.

Chillo, V. \& Anand, M. (2012) Effects of past pollution on zoochory in a recovering mixed temperate-boreal forest. Ecoscience, 19, 258-265.

Chillo, V., Anand, M. \& Ojeda, R.A. (2011) Assessing the use of functional diversity as a measure of ecological resilience in arid rangelands. Ecosystems, 14, 1168-1177.

Chillo, V. \& Ojeda, R.A. (2012) Mammal functional diversity loss under human-induced disturbances in arid lands. Journal of Arid Environments, 87, 95-102.

Chillo, V. \& Ojeda, R.A. (2014) Disentangling ecosystem responses to livestock grazing in drylands. Agriculture, Ecosystems and Environment, 197, 271-277.

Chillo, V., Ojeda, R.A., Capmourteres, V. \& Anand, M. (2016) Data from: Functional diversity loss with increasing livestock grazing intensity in drylands: the mechanisms and their consequences depend on the taxa. Dryad Digital Repository, http://dx.doi.org/10.5061/dryad.nq2j7

Cingolani, A.M., Vaieretti, M.V., Giorgis, M.A., La Torre, N., Whitworth-Hulse, J.I. \& Renison, D. (2013) Can livestock and fires convert the sub-tropical mountain rangelands of central Argentina into a rocky desert? The Rangeland Journal, 35, 285.

Cornwell, W.K., Cornelissen, J.H.C., Amatangelo, K., Dorrepaal, E., Eviner, V.T., Godoy, O. et al. (2008) Plant species traits are the predominant control on litter decomposition rates within biomes worldwide. Ecology Letters, 11, 1065-1071.

Díaz, S., Lavorel, S., McIntyre, S., Falczuk, V., Casanoves, F., Milchunas, D.G. et al. (2007) Plant trait responses to grazing - a global synthesis. Global Change Biology, 13, 313-341.

Eldridge, D.J., Poore, A., Ruiz-Colmenero, M., Letnic, M. \& Soliveres, S. (2015) Ecosystem structure, function and composition in rangelands are negatively affected by livestock grazing. Ecological Applications, 26, 1273-1283.

García, D. \& Martínez, D. (2012) Species richness matters for the quality of ecosystem services: a test using seed dispersal by frugivorous birds. Proceedings of the Royal Society, Biological Science, 279, 31063113.

Giese, M., Gao, Y.Z., Zhao, Y., Pan, Q., Lin, S., Peth, S. \& Brueck, H. (2009) Effects of grazing and rainfall variability on root and shoot decomposition in a semi-arid grassland. Applied Soil Ecology, 41, 8-18.

Grace, J.B. (2006) Structural Equation Modeling and Natural Systems. Cambridge University Press, New York, USA, 365 pp.

Guevara, J.C., Grünwaldt, E.G., Estévez, O.R., Bisigato, A.J., Blancoe, L.J., Biurrun, F.N. et al. (2009) Range and livestock production in the Monte Desert, Argentina. Journal of Arid Environments, 73, 228-237.

Hevia, V., Carmona, C.P., Azcárate, F.M., Torralba, M., Alcorlo, P., Ariño, R., Lozano, J., Castro-Cobo, S. \& González, J.A. (2015) Effects of land use on taxonomic and functional diversity: a cross-taxon analysis in a Mediterranean landscape. Oecologia, 181, 959-970.

Hoffman, B.D. \& James, C.D. (2011) Using ants to manage sustainable grazing: dynamics of ant faunas along sheep grazing gradients conform to four global patterns. Austral Ecology, 36, 698-708. 
Landsberg, J., James, C.D., Morton, S.R., Muller, W.J. \& Stol, J. (2003) Abundance and composition of plant species along grazing gradients in Australian rangelands. Journal of Applied Ecology, 40, 1008-1024.

Lovell, S., Hamer, M., Slotow, R. \& Herbert, D. (2007) Assessment of congruency across invertebrate taxa and taxonomic levels to identify potential surrogates. Biological Conservation, 139, 113-125.

Maestre, F.T., Quero, J.L., Gotelli, N.J., Escudero, A., Ochoa, V., Delgado-Baquerizo, M. et al. (2012) Plant species richness and ecosystem multifunctionality in global drylands. Science, 335, 214-218.

Magurran, A.E. (2004) Measuring Biological Diversity. Blackwell Publishing, Oxford.

Mayfield, M.M., Bonser, S.P., Morgan, J.W., Aubin, I., McNamara, A. \& Vesk, P.A. (2010) What does species richness tell us about functional trait diversity? Predictions and evidence for responses of species and functional trait diversity to land-use change. Global Ecology and Biogeography, 19, 423-431.

Moretti, M., Duelli, P. \& Obrist, M.K. (2006) Biodiversity and resilience of arthropod communities after fire disturbance in temperate forests. Oecologia, 149, 312-327.

Mouchet, M.A., Villéger, S., Mason, N.W.H. \& Mouillot, D. (2010) Functional diversity measures: an overview of their redundancy and their ability to discriminate community assembly rules. Functional Ecology, 24, 867-876.

Quiroga, R.E., Golluscio, R.A., Blanco, L.J. \& Fernández, R.J. (2010) Aridity and grazing as convergent selective forces: an experiment with an Arid Chaco bunchgrass. Ecological Applications, 20, 1876-1889.

Reynolds, J.F. \& Stafford Smith, D.M. (2001) Do humans cause deserts? Global Desertification. Do human cause deserts? Dahlem Workshop Report 88 (eds J.F. Reynolds \& D.M. Stafford Smith), pp. 1-21. Dahlem University Press, Germany.

Rodríguez, M.D. \& Ojeda, R.A. (2014) Scaling functional diversity of small mammals in desert systems. Journal of Zoology, 293, 262-270.

Sasaki, T., Okubo, S., Okayasu, T., Jamsran, U., Ohkuro, T. \& Takeuchi, K. (2011) Indicator species and functional groups as predictors of proximity to ecological thresholds in Mongolian rangelands. Plant Ecology, 212, 327-342.

Scherer-Lorenzen, M. (2008) Functional diversity affects decomposition processes in experimental grasslands. Functional Ecology, 22, 547-555.

Schmitz, O.J., Buchkowski, R.W., Burghardt, K.T. \& Donihue, C.M. (2015) Functional traits and trait-mediated interactions: connecting community-level interactions with ecosystem functioning. Advances in Ecological Research, 52, 319-343.

Semmartin, M., Aguiar, M.R., Distel, R.A., Moretto, A.S. \& Ghersa, C.M (2004) Litter quality and nutrient cycling affected by grazing-induced species replacements along a precipitation gradient. Oikos, 107, 148-160.
Thornton, P.K. (2010) Livestock production: recent trends, future prospects. Philosophical Transactions of the Royal Society of London B, $\mathbf{3 6 5}$, 2853-2867.

Vaieretti, M.V., Cingolani, A.M., Pérez Harguindeguy, N., Gurvich, D.E. \& Cabido, M. (2010) Does decomposition of standard materials differ among grassland patches maintained by livestock? Austral Ecology, 35, 935-943.

Valencia, E., Maestre, F.T., Le Bagousse-Pinguet, J., Quero, J.L., Tamme, R., Börger, L., García-Gómez, M. \& Gross, N. (2015) Functional diversity enhances the resistance of ecosystem multifunctionality to aridity in Mediterranean drylands. New Phytologist, 206, 660-671.

Wardle, D.A., Bonner, K.I. \& Barker, G.M. (2002) Linkages between plant litter decomposition, litter quality, and vegetation responses to herbivores. Functional Ecology, 16, 585-595.

Received 5 May 2016; accepted 12 August 2016

Handling Editor: Jeremy James

\section{Supporting Information}

Additional Supporting Information may be found in the online version of this article.

Table S1. Functional effect traits values/categories for vegetation, ants and small mammals used to calculate Rao's quadratic entropy index of functional diversity.

Table S2. Pearson $r$ correlation coefficients for TD vs. FD relationship, using two indices for TD: Simpson and Shannon.

Table S3. Structural equation model results for vegetation.

Table S4. Structural equation model results for small mammals.

Table S5. Structural equation model results for ants.

Fig. S1. Changes in taxonomic diversity (TD calculated with Simpson index) and functional diversity (FD) relationship after increasing livestock grazing pressure. 